\title{
Mitigating Ergonomic Injuries In Construction Industry
}

\author{
Alireza Ahankoob ${ }^{1}$, Aref Charehzehi ${ }^{2}$ \\ ${ }^{1,2}$ Department of Structure and Materials, Faculty of Civil Engineering, Universiti Teknologi Malaysia (UTM), \\ Johor Bahru, Johor, Malaysia
}

\begin{abstract}
Construction industry is one of the risky industries with high level of injuries. A musculoskeletal disorder that is one of ergonomic injuries is the most common problem in the construction industry. This type of injury can really affect the health of the people that are exposed to the hazards for a long period of time. The purpose of this paper is to discuss the way to control ergonomic risk factors in construction operations and also monitor and assess the process of program implementation to prevent or cutout ergonomic risk factors in the construction industry. The discussion gives a basic overview of ergonomic risk factors and tries to develop control measures for preventing accidents which are possible to happen in feature and also provides a comprehensive monitoring to minimize and avoid such risk factors.
\end{abstract}

Keywords - Construction, Control Measures, Ergonomic risk factors, Hazard, Musculoskeletal Disorder.

\section{INTRODUCTION}

In Greek and Latin scholars the word ergonomic refers to the relationship between human and their job background [1]. The experts mentioned ergonomic as adapting the physical environment with physiological, physical, and psychological capability and limitation of the human by considering different discipline such as anatomy, physiology, psychology, sociology, physics, and engineering. According OSHA, 1994 ergonomic is the science of "designing the job to fit the worker, rather than forcing the worker to fit the job." Thus, ergonomic is going to commence a process to eliminate all the obstacles to enhancing quality, productivity, and human performance by fitting the environment and work processes to the people [2]. As other industries the ergonomic risk factors (ERF) in construction directly related to the job features that can chip in to expose the body of the people in peril of propagation the musculoskeletal disorders [3] during long period of time. There is variety level of risk factors for different construction tasks, equipment and tools as well as the higher exposure to single ergonomic risk factors or to group of them can lead to higher rate of injuries and musculoskeletal disorders in long time [4]. These musculoskeletal disorders affect the muscles, nerves, tendons, ligaments, joints, cartilage, and spinal discs and commonly extend in small body segments such as fingers, wrists, elbows, and neck [5] hence, this paper is going to argue the risk management theory to identify ergonomic risk factors and manipulate the pragmatic approaches and effective control measures to mitigate or eliminate these ergonomic risk factors as well as applying proper monitoring tools to ensure the process is working in right way.

\section{ERgONOMIC RISK FACTORS In CONSTRUCTION}

Ergonomic risk factors are not only affecting the people immediately but also they take time to commence the affection on the person's health. Therefore, there is sufficient of time to prevent of occurring injury and cleaning the work environment from all risks by utilizing risk assessment process. The main ergonomic risk factors [6], [7] in construction industry are as follows:

(1) Awkward posture

(2) Repetition

(3) Static posture

(4) Vibration

(5) Force

(6) Contact stress

(7) Extreme temperature

\subsection{Awkward Posture}

Awkward posture is the position of the body outside of neutral that is a best location of each joint that can provide the strength and control. In the construction industry prolonged reaching, twisting, bending, kneeling, squatting, working overhead with your hands or arms, or holding fixed positions are as awkward posture [8]. Work method or workplace dimension can contribute to create awkward posture. Therefore, awkward posture can associate to raising the rate of injury in the wrist, shoulder, neck, and low back. 


\subsection{Repetition}

Performing the similar motion of the work in every few second for more than two hours without any rest and break time is mentioned as a repetition work. Repetition work can increase the rate of injury in the local tissue of the body as well as if the interaction of other ergonomic risk factors such as force, awkward posture can extend the rate of injuries [8].

\subsection{Static Posture}

The human body requires to move after a period of time that remains fixed and it is not comfortable to keep the body position without change for a long time [9]. On the other hand, performing a task in one outside of neutral position called static loading [10].

\subsection{Vibration}

Vibration is defined as any movement of the body in one fix point while using power tools or equipment while driving which can put stress on the tissues of the fingers, hand and arms [11].

\subsection{Force}

The amount of physical effort that is required by the workers to do the task or control and maintain the equipment and tools is introduced as force. Utilizing the muscles much harder than normal by applying extreme force can cause stress on the muscles, tendons and joints.

\subsection{Contact Stress}

Contact stress is created by exposure to any sharp or hard object putting localized pressure on a part of the body. Contact stress can affect the local tissue and interrupt in circulation of nerve function [12].

\subsection{Extreme Temperature}

Extreme temperature is of the environmental features that can be divided to the extreme heat and extreme cold temperature. Extreme heat can reinforce fatigue and heat stress. On the other hand, extreme cold can narrow the blood vessels and decline sensitivity and harmonization of body part.

\section{RISK MANAGEMENT THEORY}

There are different ways and methods that can be used to minimize ergonomic risk factors. Risk management theory [13] is one of the practical methods to prevent ergonomic injury. The terms Risk Management and Risk Assessment are often used interchangeably; however, as a complete process involves identification, assessment, control and review. It is clear that minimizing and avoiding injuries required identification of hazard and risk assessment process [9] nevertheless; the main issue after the risk assessment is related to selecting suitable control measures and reviewing to identify new hazards, and monitoring the rate of control measures effectiveness and work process.

\subsection{Hazard identification}

Hazards contain anything that can cause harm and sometime death hence hazard identification is the main element to control the risk and decline ergonomic injuries. Depend on type of work and type of hazards there are different methods of hazard identification such as hazard check list, direct inspection, considering material safety data sheets, and so on. The result of identification contains hazard sources, and the area of the workplace or work process where it occurs.

\subsection{Risk assessment}

Although ergonomic risk factors are not going to commence injury immediately after exposure, assess the risk is a critical process to identify the magnitude of injury and the number of people that are exposed to the risk factors. Utilizing risk table is a common method to transfer the risk assessment of likelihood and consequences into the level of risk then if it is not tolerable the system required to pick reasonable controlling measure to decrease the rate of danger and injury.

\subsection{Risk control}

Manipulating proper method and tools regarding the situation and the magnitude of risk is critical to preventing the risk. According ergonomics awareness workbook there are five principles to control ergonomic risk factors that are as follows:

Control measurement of risk factors:

- Elimination of hazard

- Substitution 
- Engineering controls

- Administrative controls

- Personal protective equipment (PPE)

\subsubsection{Elimination of hazard}

This measure is defined as removing the hazard or hazardous event from the workplace. This is the most effective control measures. A good example of elimination would be to use an electric forklift truck rather than a gas operated forklift truck to eliminate carbon monoxide in a warehouse.

\subsubsection{Substitution}

Substitution is defined as substituting or replacing a hazardous practice with a less hazardous one. When a hazard cannot be eliminated completely, the second best solution is replacing the dangerous condition. An example of this control measure would be using paint that does not contain lead-based pigments. A potential problem is when the product being used as a substitute is as dangerous as the original.

\subsubsection{Engineering Controls}

If the hazard cannot be eliminated, substituted and engineering control is the next preferred measure. For example, machine guards, backup alarms, guardrails, covers, slip resistant surfaces, and using machines to move heavy objects instead of carrying them.

\subsubsection{Administrative Controls}

Administrative Controls or changing labor practices include introducing work practices that reduce the risk. Example of this strategy is: Instead of one employee exposed to a particular hazard for eight hours a day, assigning four workers to work for two hours each. This approach limits the amount of time a person is exposed to a hazard.

\subsubsection{Personal Protective Equipment}

Personal protective equipment (PPE) contains issues relating to respirators, and protective wear for the eyes, ears, face, gloves, and protective rope. PPE is the least protective way for the workers. This approach is considered only when other measures are not applicable. If equipment fails, workers are still exposed to the risk.

After considering ergonomic risk factors such as awkward posture, static posture, and excessive force and so on as hazardous events which produce bodily injuries and incidents in the future, we should identify them in the construction works and then develop control measures. The need for eliminating and controlling over them arises according to risk management theory in the workplace. However, this control requires precise monitoring and an astute safety officer to define appropriate and safe operations for workers.

This section makes an effort to focus on hazardous events and activities that usually committed at construction sites and then provides the necessary solutions to prevent accidents regarding to five principles of risk control but will be focusing more on engineering and personal protective equipment technique.

From initiation phase to completion in a construction project several activities need to be implemented. Each of these activities requires a set of resources to complete projects such as concreting, bar bending, roofing, plumbing and pipefitting. The risk of injury due to ergonomic risk factors in these operations differentiates from one stage to the other stage.

In the following, some of the hazardous tasks that may emerge during the construction process are specified and proper solutions will be recommended:

- Concreting

This act Involves pouring concrete and smoothing. Therefore, repetitive shoveling and smoothing the surface produce stress on soft tissues, nerves and finally results in back pain due to great effort to pour and smooth the surface of the concrete in a steady manner and repeating the same motions in every few seconds.

How to improve: to prevent future injuries, regular breaks and providing additional suitable tools such as plasticizers reduce repetitive works and increase efficiency.

- $\quad$ Steel Structural Works

General tasks within steel works involve lifting, holding, erecting and fixing the steel structure. The nature of the steel work intensifies the possibility of the inquiries by the installation of steels thereof entail excessive force, use of power tools, awkward postures, and lifting, falling and static postures [14]. Falls are the leading cause of deaths in the construction industry and falls from as little as 4 to 6 feet can result in serious accidents or sometimes death. Moreover, in most cases, multiple concurrent operations are being performed like lifting and holding beams in a high altitude in the air while bolting and aligning columns and bolts to each other. How to improve: new methods of construction such as Industrial Building System (IBS) and pre-assembly of steel structure will reduce the risk of injury. Furthermore, it is practicable to mitigate the excessive force by 
simplifying the joints [15]. It is recommended to provide Guardrails, Safety Net and Personal fall arrest system to prevent falling. The personal fall arrest system involves a harness, anchorage, and line tools. As a matter of fact the employer must provide this equipment and training on how to use it.

- Plumbing and Pipefitting

Different types of piping material require specific jointing methods. Most of the times, installation of pipes is not complementary to ergonomic principles. Furthermore, a large number of these installations require extensive overhead work and high hand force. Clinching hangers in an unstable situation results in twisting and static loading and consequently put stress on the neck, shoulders and arms.

How to improve: during designing of the joints and identifying the vertical and horizontal ducts for piping, the designer should consider and review the ergonomic principles.

- $\quad$ Roofing and Tiling

Problems associated with roofing and tiling depends on the different designs of roof. However, the main hazards in this section are material handling and slipping [15]. Each of the materials such as sheet materials, tiles and waterproofing membranes demand a huge number of twisting and handling tasks of massive unit materials per square meter of area [16, 17].

How to improve: providing passenger and material hoist, ladder type material lifts promotes the lifting of unit materials to the roof. Furthermore, using of roof jacks and planks aims to guard against falls. For having a better control over activities, workers need to keep the area around the top and bottom of a ladder clear.

- Reinforcing

In most cases the fastening and tying of rebar involves repetitive and fast movements of the wrist when bending to tie rebar precisely. These motions lead to awkward and static posture together with repetition.

How to improve: the amount of time spent on fastening and fixing can be decreased by using fabric rather than bar reinforcing. This also lowers the number of awkward postures and bending. Moreover, the worker is able to fix repair at top level by using trestles.

- Installation of Formwork

Generally, during erection and assembly of formworks, huge amounts of twisting, squatting, kneeling and working with the hands overhead are required along with the hands overhead are required along with excessive force [15]. So far as is possible, these hazardous motions should be highlighted and alternative methods to be introduced. For this purpose, changing design must be considered as the first step.

How to improve: there are several recommendations in this area. One solution is the simplification of wall forms, table forms, columns and beams which can be handled by carnage whereby the manual handling and excessive force will be eliminated.

The next solution is to use pre-cast elements as much as is possible to reduce the amount of formwork and in-situe fixing reinforcing. Furthermore, pre-stressed concrete is another alternative to decrease repair reinforcing.

- Masonry Works

Brickworks contribute to most work hazards in construction operations. Handling and lifting nearly 600 to 1000 bricks in a working day put strong stress on the back and shoulder with high forces putting localized pressure on a part of the body [18]. It is clear that these lifting are accompanied with great numbers of twist flexion [3].

How to improve: designing tools which involve hand-holds to facilitate and develop lifting bricks.

- Floor Finishes

Floor finishes in all buildings require workers to use their hands and knees as a hammer. Hence, contact stress together with kneeling and bending is appeared in processes. These motions will irritate local tissues and interfere with circulation and nerve function.

How to improve: adding fixture to tools and providing tripod benches reduces the need for cutting tiles at floor level. By this approach, workers spend less time putting their knees and palms on the hard surface of the tiles which palliates pressure on soft tissues.

- Electrical Work

This type of construction works demands high pinching and gripping forces which involves a large amount of wrist motion that leads to putting stress on the arms and shoulders. Lots of hand tools are needed to fix connections in different kinds of body shapes.

How to improve: designers have a significant role to provide appropriate access to each section of the building during the construction phase.

Workers need to stay about 10 feet ( 3 meters) away from dangerous aerial cable during maintenance, installation or other activities. If they are working at a high altitude on scaffolding or on a ladder they should check for the presence of aerial cables before starting their work.

- Painting 
The existence of specific areas such as roof area intensifies the process of painting. Since overhead repetitive motions put substantial pressure on the back and shoulders [19, 20].

How to improve: designers should consider tools such as spraying equipment for painting specific area with difficult access. Another recommendation focuses the kind of posture of the worker on the supporter to conduct his duty.

3.4. Monitoring and Review - Effective Ergonomic Risk Factors Monitoring (EERFM)

In monitoring process, frequent hazard identification and risk assessment process to determine and assurance that the solution is working in good manner is necessary also if there is any problems, take appropriate changes on time. The process of Effective Ergonomic Risk Factors Monitoring (EERFM) requires a coherent evaluation program to ensure the program will meet the requirements. The effective EERFM program contains adequacy of references in writing, proper training program, implementation guideline, enforcement in doing the program, and suitable evaluation program to achieve the goal and reduce the rate of injuries. The following section is going to discuss the way to assess the EERFM process.

\section{EERFM ASSESSMENT PROCESS}

When the EERFM program is created and implemented on site, the effectiveness of the program is needed to be assessed frequently. Solution assessment in EERFM is often given up and all people go to solve the next problem. It is important to regularly monitor the steps, especially when there are changes in the workplace or new technology, equipment, tools and standards are introduced. The first step in assessment is collecting information about EERFM implementation and the person's requirement that must be collected by documentation review, questionnaires, interviews and direct inspections. In the second step the collected information must be compared with program requirements and actual goal to obtain the strengths and weakness of EERFM program and providing a report on them. If there is any deviation from actual plan and goal, corrective action should be used and EERFM must be adjusted again to achieve the particular purpose "Fig. 1".

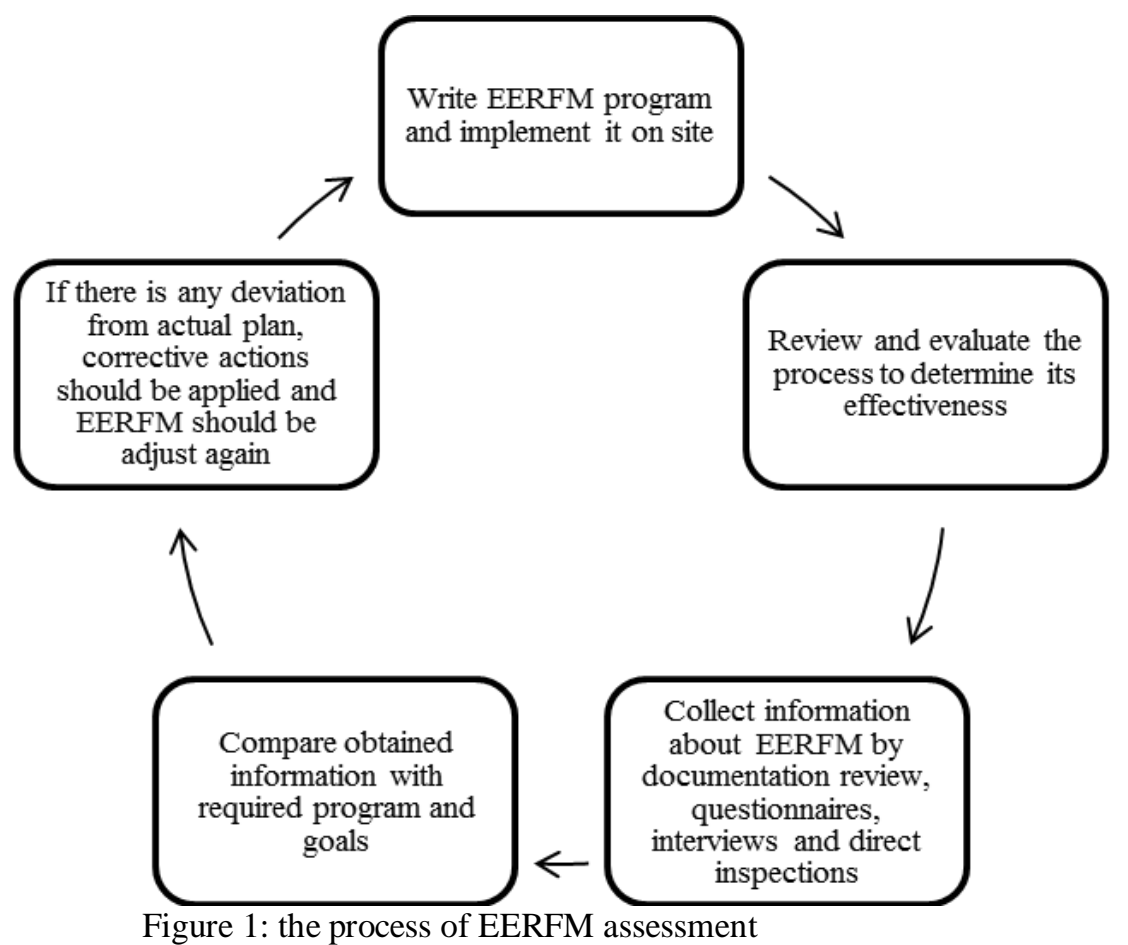

\subsection{Information Gathering Methodology}

Safety assessment must consider the main key element such as management commitment and participation of different parties such as senior management, supervisors and employees in health and ergonomic system. The assessment and information gathering can be done by four methods that are as follows:

\subsubsection{Documentation and Review}

The company must provide a checklist to demand information, documents, and also monitor the company's health and safety documentation and records to evaluate the key elements of EERFM program. The 
report should be written after evaluation to identify strengths and weaknesses and also make recommendation to readjust EERFM program.

\subsubsection{Workplace Observation}

Direct workplace observation covers all the work area such as material handling, lifting, lifting devices, workplace design and environment, work processes and routines to detect unsafe acts and unsafe conditions that are related to the strength and weakness of the program that is implemented to the site.

\subsubsection{Questionnaires}

A questionnaire will be developed by the company to distribute between parties in different level that are responsible to implement the EERFM program or may be exposed to the ergonomic risk factors directly therefore, from top level management personnel to low level worker may respond. The result of questionnaire will compare with actual work and to identify the weakness ad strength of the program and make recommendation to improve it.

\subsubsection{Interview}

Interview with manager, supervisor, worker and also safety and health committee regarding the sufficiency and efficiency of the EERFM program in construction site can assist to detect the positive and negative points of program to improve it.

\subsection{Comparison}

After information collection and providing reports, the result should be reviewed and analyze to obtain the weaknesses and strength points of the program.

\subsection{Corrective Action Plan}

According to points if there is any deviation from actual plan, the corrective action should be applied to readjust the program and achieve the goal in a short period of time. The corrective action process is exhibited in "Fig. 2".

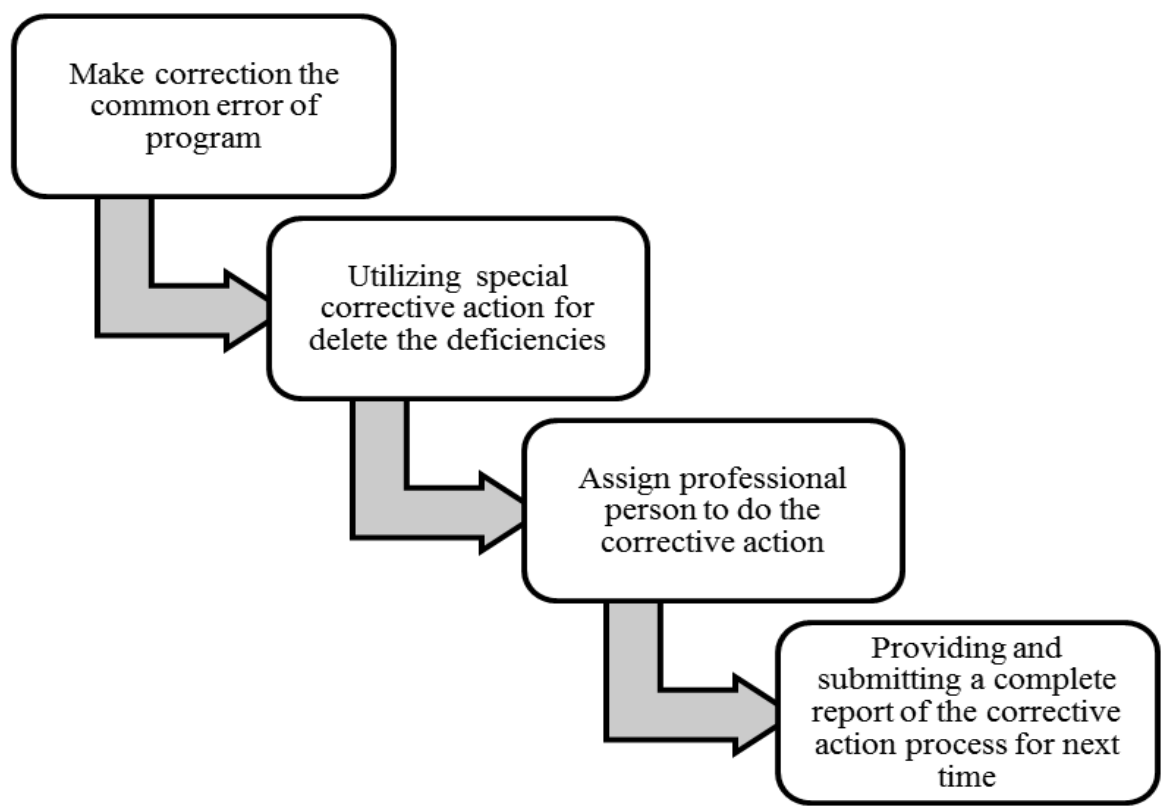

Figure 2: the corrective action process

\section{DISCUSSION}

Applying the EERFM strategy with appropriate control measures concurrently in a regular basis remove the barrier to quality, productivity and human performance. By removing obstacles, the human performance will be increased and leads to ergonomic objectives. When ergonomic goals are fulfilled, the direct and indirect costs of injuries will be declined. On the other hand, by providing a safe and healthful work environment the workers will be able to implement the task in the right manner and modify the productivity rate by reduce waste of time and cost. It is clear achieving ergonomic objectives is not just utilizing a simple checklist and guideline carelessly or using just a common sense as regards ergonomic-based program must be 
updated with real data and information that are obtained by a regular surveying through the work process directly.

\section{CONCLUSION}

The main objective of the ergonomic is to make certain the capacity of humans is considered in the system and is no exceeded from the optimal. Optimal means balancing the people requirements with the real life limitations. Therefore, at the end it will be possible to meet the below objectives in the construction site:

- Improve Quality

- Adopt humane capability with optimal situation

- Balance requirement and limitation

- Increase Productivity

- Make easy the human performance

- Provide a safe and healthy working environment

- Reduce disorders

- Decrease costs

- Improvement of moral of the workers.

In this study ergonomic risk factors hidden in construction activities analyzed and some continuous improvements provided to prevent future risk of injuries. The study also used risk management theory as a basic structure to identify hazards. The process of the risk management theory with proper monitoring and control measurement leads to mitigate the risk of ergonomic factors which are considered as the hazardous events to workers exposed to these factors for a long period of time.

\section{REFERENCES}

[1]. Te-Hsin,P \& Kleiner,B.H., New developments concerning the occupational safety and health act, Journal of Managerial Law, 43, No.1/2, 2001, 138-146.

[2]. Tayyari,F \& Smith, J.L., Occupational Ergonomics: Principles and applications, $1 \& 19$ (London: Chapman \& Hall 1997).

[3]. Rwamamara, R. A., The healthy construction workplace: Best practices in the Swedish construction industry to prevent workrelated musculoskeletal disorders among construction workers, Licentiate diss., Luleå University of Technology, 2005.

[4]. William J., Wiehagen and Fred C. T., Ergonomic assessment of musculoskeletal risk factors art Four Mines States, Underground Coal, Surface Copper, Surface phosphate and underground limestone, 2004.

[5]. Cohen A.C., Gjessing C.C.,Fine L.J.,Bernard B.P.,McGlothlin J.D., Elements of ergonomics programs: A primer based on workplace evaluations of musculoskeletal disorders, National Institute for occupational safety and health, DHHS (NIOSH) Publication, 1997, No.97-117.

[6]. Hagberg M., Silverstein B., Wells R., Smith M.J., Hendrick H.W, Carayon P, et al., Work related muskelosketal disorders (Taylor and Francis, 1995).

[7]. Bongers P.M.,Kremer A.M.,Ter Laak J., Are psychosocial factors risk factors for symptoms and signs of the shoulder, elbow or hand /wrist? A review of the epidemiological literature. American Journal of Industrial Medicine, 41(5), 2002, 315-342.

[8]. Amstrong J.J., Lifshita Y., Evaluation and design of jibs for control of cumulative trauma disorders, Ergonomic interventions to prevent musculoskeletal injuries in the industry (Lewis Publisher, Chelsea, 1987).

[9]. Kroemer, K. H. E. And E. Grandjean, Fitting the Task to the Human, A Textbook of Occupational Ergonomics, 5 (London, Taylor and Francis, 1997).

[10]. National Research Council and The Institute of Medicine, Muskelosketal disorders and the workplace: Low back and upper extremities. Panel on Musculosketal Disorders and the workplace. Commission on Behavioral and Social Sciences and education. National Academy Press, Washington, DC, 2001.

[11]. Kinsella, G., Prior, M., Sawyer, M., Murtagh, D., Eisenmajer, R., Anderson, V., et al., Neuropsychological deficit and academic performance in children and adolescents following traumatic brain injury. Journal of Pediatric Psychology, 1995, $20,753-767$.

[12]. Fraser, T.M, The worker at work: A textbook concerned with men and women in the workplace. (New York, Taylor \& Francis, 1989).

[13]. Nocco, B. W., \& Stulz, R. M., Enterprise risk management: Theory and practice, Journal of Applied Corporate Finance, 18 (4), 2006, 8-20.

[14]. Hsiao, H. \& Simeonov, P., Preventing falls from roofs: a critical review, Ergonomics, 2001, 44, 537-561.

[15]. Gibbons, B. And S. Hecker., Participatory approach to ergonomic risk reduction: Case study of body harnesses for concrete work, Proc. 2th CIB Conf. of Working Commission W99 Implementation of Safety and Health on Construction Sites, Honolulu, Hawaii, 1999, 373-380.

[16]. Kemmlert, K. \& Lundholm, L., Slips, trips and falls in different work groups - with reference to age and from a preventive perspective, Applied Ergonomics, 2001, 32, 149-153.

[17]. Lipscomb, H. J., Glazner, J. E., Bondy, J., Guarini, K. \& Lezotte, D, Injuries from slips and trips in construction, Applied Ergonomics, 2006, 37, 267-274.

[18]. Graves, R.J. 1992. Using ergonomics in engineering design to improve health and safety. Safety Science, 1992, 15, 327-349.

[19]. Eastman Kodak, Ergonomic Design for people at work,2 (John Wiley \& Sons, 1986).

[20]. Gauchard, G., Chau, N., Mur, J. M. \& Perrin, P., Falls and working individuals: role of extrinsic and intrinsic factors. Ergonomics, 2001, 44, 1330-1339. 